\title{
The potential of tailoring the conditions of steam explosion to produce xylo- oligosaccharides from sugarcane bagasse
}

\author{
Ana Flavia Azevedo Carvalho ${ }^{\mathrm{a}, \mathrm{b}, \mathrm{c}, 1}$, Wilian Fioreli Marcondes ${ }^{\mathrm{d}, 1}$, Pedro de Oliva Neto ${ }^{\mathrm{b}}$, \\ Glaucia Maria Pastore $^{\mathrm{c}}$, Jack N. Saddler ${ }^{\mathrm{a}}$, Valdeir Arantes ${ }^{\mathrm{d}, *}$ \\ a Department of Wood Science, Forest Sciences Centre, University of British Columbia, 2424 Main Mall, V6TIZ4 Vancouver, BC, Canada \\ ${ }^{\mathrm{b}}$ Associated Laboratory of Bioenergy Research Institute (IPBEN), Bioprocess Unit, São Paulo State University (UNESP), Av. Dom Antonio, 2100, 19806-380 Assis, SP, \\ Brazil \\ ${ }^{\mathrm{c}}$ Department of Food Science, School of Food Engineering, State University of Campinas (UNICAMP), Rua Monteiro Lobato, 80, 13083-862 Campinas, SP, Brazil \\ d Department of Biotechnology, Lorena School of Engineering, University of São Paulo (USP), Lorena, SP, Brazil
}

\section{A R T I C L E I N F O}

\section{Keywords:}

Xylo-oligosaccharides

Steam explosion

Sugarcane bagasse

Xylan

\begin{abstract}
A B S T R A C T
In this study, the potential of the steam explosion (SE) method to produce high levels XOS from sugarcane bagasse, a xylan-rich hemicellulosic feedstock, was assessed. The effect of different operating conditions on XOS production yield and selectivity were investigated using a mini-pilot scale SE unit. The results show that even under a non-optimized condition $\left(190{ }^{\circ} \mathrm{C}, 5 \mathrm{~min}\right.$ and $0.5 \% \mathrm{H}_{2} \mathrm{SO}_{4}$ as catalyst), SE led to about $40 \%$ xylan recovery as XOS, which was comparable to the well-known, multi-step, enzymatic production of XOS from alkalineextracted xylan, and other commonly employed chemical methods. In addition, the XOS-rich hydrolysate from SE constituted of greater diversity in the degree of polymerization, which has been shown to be desirable for prebiotic application.
\end{abstract}

\section{Introduction}

Xylo-oligosaccharides (XOS) are carbohydrates made up of 1,4linked $\beta$-xylose backbone naturally present in fruits, vegetables and honey (Vázquez et al., 2000), but it can also be produced from the structural hemicellulosic polysaccharide xylan found in plant cell walls of gramineas and hardwood (Nimz, 1984). Their application is very diverse and covers areas such as biodegradable oxygen barrier film, emulsifiers, vegetable gum used as food thickeners, reinforcing agent in cellulose pulp, adhesives, and more recently also as dietary fibers (Kamm and Kamm, 2004; Mäkeläinen et al., 2010; Vázquez et al., 2000). As the industrial interest in XOS grows (Figueiredo et al., 2016; Vázquez et al., 2000), xylan-rich plant materials (lignocellulose) holds the greatest potential as raw material for large scale production of XOS due to their worldwide abundance (Ebringerová and Heinze, 2000).

XOS can be produced by alkaline-based treatment to first extract the xylan, which due to the high molecular weight (degree of polymerization higher than 120) (Panthapulakkal et al., 2015), needs to undergo an acid or enzymatic hydrolysis step to obtain XOS (Vázquez et al., 2000). Alkaline treatment has the advantages of requiring temperature lower (below $140{ }^{\circ} \mathrm{C}$ ) than the used in acidic treatment and has low carbohydrate loss, but also has the disadvantages of consuming of part of the alkali agent during the reaction and the necessity of an additional hydrolysis step to breakdown the high DP xylan chains to XOS (Hendriks and Zeeman, 2009; Lee et al., 2014). Enzymatic hydrolysis (EH) of the extracted xylan is carried out with endo-xylanase that catalyze the depolymerization of the xylan chain releasing XOS, mainly xylobiose (Javier et al., 2007).

XOS can also be produced by acidic treatments to hydrolyze the more thermally labile hemicellulose. The main products recovered in the hydrolysate are oligomers and monomers, but sugar-degradation products can also be generated depending on the severity of the treatment (Santucci et al., 2015; Schell et al., 2003).

The conditions chosen for the treatment in acidic medium also define its category, which may be concentrated acid (CA), dilute acid (DA) or autohydrolysis (AH) (Hu and Ragauskas, 2012). In CA and DA treatments, an acid catalyst is added into the medium. The most commonly used acid catalysts are $\mathrm{H}_{2} \mathrm{SO}_{4}, \mathrm{SO}_{2}, \mathrm{HCl}, \mathrm{HNO}_{3}$ and $\mathrm{H}_{3} \mathrm{PO}_{4}$ (Carvalheiro et al., 2008; Hu and Ragauskas, 2012). The amount of the acid catalyst added defines whether the process is concentrated or diluted. In general, the concentration of the acid catalyst is in the range of $40-72 \%(w / w)$ for CA and less than $4 \%(w / w)$ for DA (Carvalheiro

\footnotetext{
* Corresponding author.

E-mail address: valdeir.arantes@usp.br (V. Arantes).

${ }^{1}$ Authors with equal contribution.
} 
et al., 2008; Hu and Ragauskas, 2012; Pedersen and Meyer, 2010). DA treatments are carried out at temperatures between 120 and $210{ }^{\circ} \mathrm{C}$ for a few seconds to hours (Hu and Ragauskas, 2012), and it is more selective for hydrolysis of the hemicelluloses than cellulose, unlike the CA treatment that tends to hydrolyze all carbohydrates due to the higher severity of the treatment (Carvalheiro et al., 2008). Some advantages of DA treatment over CA treatment is the need of less corrosion-resistant reactors, less toxic and hazardous treatment, and simpler downstream processes because it contains less acid to be neutralized and removed from the hydrolysates (Lee et al., 2014). When no acid catalyst is added to the medium, the acidic treatment is named autohydrolysis (AH). In this case, hemicellulose hydrolysis is performed by the hydronium ion of the water or by compounds released in the medium during the reaction, like acetic acid from the acetyl groups found hemicellulose (Lee et al., 2014). Typically, treatment temperature and time for $\mathrm{AH}$ are in the range of $120-260^{\circ} \mathrm{C}$ and from some minutes to a few hours, respectively (Hu and Ragauskas, 2012). Similar to DA treatments, the main hydrolysis products are oligomers and monomers, but at higher severity conditions these products can be degraded to sugar-degradation products. The advantages of $\mathrm{AH}$ treatment are the no need for corrosion resistant reactors and lower cost for the downstream step, since there is no residual acid to be neutralized or recovered (Abdul Khalil et al., 2012; Lee et al., 2014; Pedersen and Meyer, 2010). Therefore, it is expected that under mild and low severity conditions the hydrolysis product from acidic treatment of xylan-rich lignocellulosic biomass would be mainly XOS (Vallejos et al., 2015). In addition, compared to alkaline treatment followed by acid or enzymatic hydrolysis for production of XOS, the acidic pretreatments DA and AH seems suitable for XOS production due the lower number of process steps required and shorter reaction time.

Acidic treatments for production of XOS has been reported in various types of vessels (i.e. high pressure vessels, autoclave, and reactors such as plug flow, percolation, and pressure reactors) (Hendriks and Zeeman, 2009; Hu and Ragauskas, 2012; Manorach et al., 2015; Patel et al., 2017). Alternatively, acidic treatments such as DA and HA can also be carried out using a steam explosion (SE) vessel. During SE treatment, plant biomass is fed into the SE vessel and subjected to high pressure and temperature for several seconds to few minutes, followed by a quick decompression that promotes defibrillation of the treated biomass (Chandra et al., 2015; Rocha et al., 2012) .

A great amount of research and development has already been done in SE, and today it is widely recognized that SE is a low-cost and effective treatment for hemicellulose solubilization for a wide varied of lignocellulosic feedstocks (Bacovsky et al., 2013). Consequently, SE has become the preferred method for hemicellulose solubilization, except at the laboratory bench scale (Hu and Ragauskas, 2012). However, past studies on SE have mainly focused on hemicellulose hydrolysis to its monomeric constituents and the suitability of SE for hemicellulose hydrolysis to oligomers is still unknown.

Sugarcane bagasse is an abundant industrial residue with a hemicellulosic fraction almost exclusively made up xylan. In this context, the aim of this work was to investigate the suitability of using SE treatment to selectively hydrolyze the xylan in the xylan-rich sugarcane bagasse into XOS at high yield.

\section{Material and method}

\subsection{Sugarcane bagasse characterization}

The sugarcane bagasse utilized in this study was obtained from the sugar mill Usina Água Bonita (Tarumã/São Paulo, Brazil). The carbohydrate (cellulose and hemicellulose), acid insoluble (AIL) and soluble lignin (ASL) contents in the sugarcane bagasse were quantified according to Sluiter with minor modifications (Sluiter et al., 2008). Briefly, a sample was oven dried and ground in a hammer mill to pass through a 20-mesh screen. The amount of inorganic material, either structural or extractable, in the bagasse, hereafter referred to simply as ash was determinate by the percentage of residue of bagasse remaining after dry oxidation at 550 to $600{ }^{\circ} \mathrm{C}$ in a muffle furnace. Extractives were determined by subjecting the dried bagasse to a two-step extraction procedure using water and ethanol. The extracted bagasse was then subjected to a two-step acid hydrolysis with $\mathrm{H}_{2} \mathrm{SO}_{4}$ for conversion of the insoluble carbohydrates into soluble monomeric sugars. The solid residue was washed with deionized water, oven dried and used to quantify AIL gravimetrically. The filtrate was analyzed for monomeric sugars by High-Performance Liquid Chromatograph (HPLC - DX-500, Dionex Corp., Sunnyvale, US) as described in 2.6. Purified water (MilliQ) was used as eluent at a flow rate of $0.5 \mathrm{~mL} / \mathrm{min}$. The filtrate was also analyzed for ASL by measuring the absorbance at $205 \mathrm{~nm}$ and with $\varepsilon=25$ (Dence, 1992).

\subsection{Steam explosion (SE)}

Batch SE treatments were carried in a 2-L StakeTech II steam gun (Stake Technologies, Norval/Ontario, Canada) according to Olsen et al. (2015). Impregnation of bagasse with $\mathrm{SO}_{2}$ or $\mathrm{H}_{2} \mathrm{SO}_{4}$ was performed as described elsewhere (Olsen et al., 2012). For $\mathrm{SO}_{2}$-catalyzed treatments, $50 \mathrm{~g}$ (dry weight) of sugarcane bagasse in plastic bags were injected with gaseous $\mathrm{SO}_{2}$, (Praxair Canada Inc., Mississauga, Ontario) and immediately sealed and left overnight (approximately 12-14 h) prior to $\mathrm{SE}$ treatment. For $\mathrm{H}_{2} \mathrm{SO}_{4}$-catalyzed treatments, $50 \mathrm{~g}$ (dry weight) of sugarcane bagasse in plastic bags were impregnated with dilute $\mathrm{H}_{2} \mathrm{SO}_{4}$ to reach the desired concentration and $50 \%$ moisture content of the bagasse. The dilute $\mathrm{H}_{2} \mathrm{SO}_{4}$ solution was added to the bagasse with a spray bottle to ensure homogeneous uptake before SE treatment was carried out. Sugarcane bagasse without impregnation with $\mathrm{SO}_{2}$ or $\mathrm{H}_{2} \mathrm{SO}_{4}$, thereafter referred to as autohydrolysis SE treatment, was also carried out in batches of $50 \mathrm{~g}$. The SE operation conditions (reaction time, temperature, and catalyst type and concentration) for all treatments are listed in Table 1. After each treatment batch, the exploded slurry in the collecting vessel was removed and filtered by vacuum filtration using a Buchner funnel to separate the hydrolysate (the watersoluble fraction, WSF) from the water insoluble fraction (WIF). The WSFs containing the products of hemicellulose solubilization were frozen at $-20^{\circ} \mathrm{C}$ and later thawed for analyses.

\subsection{Autoclave (AC)}

Sugarcane bagasse was treated in an autoclave using an $\mathrm{Amsco}^{\circledR}$ Centry $^{\mathrm{TM}}$ Medium Steam SG-120 Sterilizer (Steris Corporation, Erie/ USA). $26 \mathrm{~g}$ of bagasse (dry weight) was loaded in a $1 \mathrm{~L}$ glass flask, followed by addition of $247 \mathrm{~mL}$ of diluted $\mathrm{H}_{2} \mathrm{SO}_{4}(\mathrm{M})$. The closed flask containing the $\mathrm{H}_{2} \mathrm{SO}_{4}$-impregnated bagasse was then autoclaved according to the conditions shown in Table 1. After cooled at room temperature, the treated bagasse was filtered by vacuum filtration using a Buchner funnel to separate the WSF and the WIF. The WSFs containing the products of hemicellulose solubilization were frozen at $-20^{\circ} \mathrm{C}$ and later thawed for analyses.

\subsection{Pressurized reactor $(P R)$}

A custom-built, four-vessels, pressurized rotating reactor made by Aurora Products Ltd. (Savona/BC, Canada) was also used to treat sugarcane bagasse. $50 \mathrm{~g}$ of bagasse (dry weight) was loaded in the reactor vessel followed by addition of $450 \mathrm{~mL}$ of diluted $\mathrm{H}_{2} \mathrm{SO}_{4}(0.1 \%$ or $0.5 \% \mathrm{w} / \mathrm{w}$ ), and closed. Treatment conditions are listed in Table 1. After cooled at room temperature in a running water batch, the reactor vessel was opened, the treated bagasse was collected and filtered by vacuum filtration using a Buchner funnel to separate the WSF and the WIF. The WSFs containing the products of hemicellulose solubilization was frozen at $-20^{\circ} \mathrm{C}$ and later thawed for analyses. 
Table 1

Methods and operational conditions (temperature, time, catalyst type and concentration) used to treat sugarcane bagasse.

\begin{tabular}{|c|c|c|c|c|}
\hline Code & Treatment & Temperature $\left({ }^{\circ} \mathrm{C}\right)$ & Time (min) & Catalyst type and concentration $(\% \mathrm{w} / \mathrm{w})^{1}$ \\
\hline SE01 & Steam explosion & 130 & 15 & Autohydrolysis \\
\hline SE02 & Steam explosion & 130 & 15 & $\mathrm{SO}_{2} 0.9 \%$ \\
\hline SE03 & Steam explosion & 130 & 30 & $\mathrm{SO}_{2} 0.9 \%$ \\
\hline SE04 & Steam explosion & 130 & 30 & Autohydrolysis \\
\hline SE05 & Steam explosion & 150 & 15 & $\mathrm{SO}_{2} 0.9 \%$ \\
\hline SE06 & Steam explosion & 150 & 15 & Autohydrolysis \\
\hline SE07 & Steam explosion & 150 & 30 & Autohydrolysis \\
\hline SE08 & Steam explosion & 150 & 30 & $\mathrm{SO}_{2} 0.9 \%$ \\
\hline SE09 & Steam explosion & 150 & 30 & $\mathrm{SO}_{2} 3.0 \%$ \\
\hline SE10 & Steam explosion & 150 & 30 & $\mathrm{H}_{2} \mathrm{SO}_{4} 0.1 \%$ \\
\hline SE11 & Steam explosion & 150 & 30 & $\mathrm{H}_{2} \mathrm{SO}_{4} \quad 0.5 \%$ \\
\hline SE12 & Steam explosion & 150 & 15 & $\mathrm{H}_{2} \mathrm{SO}_{4} \quad 1.0 \%$ \\
\hline SE13 & Steam explosion & 150 & 30 & $\mathrm{H}_{2} \mathrm{SO}_{4} \quad 1.0 \%$ \\
\hline SE14 & Steam explosion & 170 & 15 & $\mathrm{H}_{2} \mathrm{SO}_{4} \quad 1.0 \%$ \\
\hline SE15 & Steam explosion & 170 & 30 & $\mathrm{H}_{2} \mathrm{SO}_{4} \quad 1.0 \%$ \\
\hline SE16 & Steam explosion & 190 & 5 & $\mathrm{H}_{2} \mathrm{SO}_{4} 1.0 \%$ \\
\hline SE17 & Steam explosion & 190 & 5 & $\mathrm{H}_{2} \mathrm{SO}_{4} \quad 0.5 \%$ \\
\hline SE18 & Steam explosion & 200 & 5 & $\mathrm{SO}_{2} 3.0 \%$ \\
\hline AC01 & Autoclave & 121 & 60 & $\mathrm{H}_{2} \mathrm{SO}_{4} 0.1 \%$ \\
\hline AC02 & Autoclave & 132 & 60 & $\mathrm{H}_{2} \mathrm{SO}_{4} \quad 0.1 \%$ \\
\hline PR01 & Pressurized reactor & 130 & 30 & $\mathrm{H}_{2} \mathrm{SO}_{4} \quad 0.1 \%$ \\
\hline PR02 & Pressurized reactor & 150 & 15 & $\mathrm{H}_{2} \mathrm{SO}_{4} \quad 0.5 \%$ \\
\hline PR03 & Pressurized reactor & 150 & 15 & $\mathrm{H}_{2} \mathrm{SO}_{4} 0.1 \%$ \\
\hline
\end{tabular}

$1 \% \mathrm{w} / \mathrm{w}$ relative to the dry mass.

\subsection{Xylan extraction and enzymatic hydrolysis (EH)}

The extraction of arabinoxylan (xylan) from sugarcane bagasse was carried according to the method described by Zilliox and Debeire (1998) (ZD method) and adapted by Akpinar et al. (2009). Briefly, washed and ground sugarcane bagasse was prepared at $60^{\circ} \mathrm{C}$ for $16 \mathrm{~h}$ in $400 \mathrm{~mL}$ of deionized water, and drained. Thereafter, $250 \mathrm{~mL}$ of a $24 \%$ $(\mathrm{w} / \mathrm{v}) \mathrm{KOH}$ and $1 \%(\mathrm{w} / \mathrm{v}) \mathrm{NaBH}_{2}$ solution was added to $8 \%(\mathrm{w} / \mathrm{v}) \mathrm{su}-$ garcane bagasse, and let react for $3 \mathrm{~h}$ at $35^{\circ} \mathrm{C}$. The liquid fraction was filtered with gauze until no solid was observed in the liquid phase. The xylan in the liquid fraction was precipitated using a mixture of $60 \%(\mathrm{v} /$ v) ethanol, $6.7 \%(\mathrm{v} / \mathrm{v})$ acetic acid and $33.3 \%(\mathrm{v} / \mathrm{v})$ xylan solution. The precipitated material (oxylan) was centrifuged at $4000 \times \mathrm{g}$ for $15 \mathrm{~min}$. This material was washed 4 times with 1 vol ethanol solution $(50 \%$ ethanol, $50 \%$ deionized water and $0.5 \% \mathrm{w} / \mathrm{v}$ EDTA): 1 vol oxylan, before being dried at $60^{\circ} \mathrm{C}$.

The $\mathrm{EH}$ of the extracted xylan was carried out at conditions previously optimized (Figueiredo et al., 2016). Briefly, 7\% consistence (w/ v) xylan in an Erlenmeyer $(125 \mathrm{~mL})$ with $40 \mathrm{~mL}$ of acetate buffer $(0.5 \mathrm{M}$, $\mathrm{pH}$ 5.0) was treated with an Aspergilus fumigatus M51endoxylanase ( $350 \mathrm{U} / \mathrm{g}$ of substrate) produced in Erlenmeyer as described elsewhere (Carvalho et al., 2015). The hydrolysis was incubated at $50^{\circ} \mathrm{C}$ for $48 \mathrm{~h}$ in shaker (model TE 405; Tecnal) at $130 \mathrm{rpm}$. The hydrolysate was stopped by boiling in water bath for $10 \mathrm{~min}$ and centrifuged at $4000 \times \mathrm{g}$ for $15 \mathrm{~min}$.

\subsection{Determination of monomeric sugars}

The content of the monomeric sugars (xylose, glucose and arabinose) released in the hydrolysate following SE, AC, PR, and EH treatments were quantified by HPLC using a Dionex system (DX-500, Dionex Corp., Sunnyvale, US) equipped with an ion exchange CarboPac PA-1 column equilibrated with $1 \mathrm{M} \mathrm{NaOH}$ and eluted with nanopure water at a flow rate of $1 \mathrm{~mL} / \mathrm{min}$, and a ED40 electrochemical detector (gold electrode). Prior to injection, diluted samples were filtered through $0.45 \mu \mathrm{m}$ HV filter (Millipore, MA, U.S.). Analytical-grade standards of xylose, glucose, and arabinose (Sigma-Aldrich) were used to quantify the concentration of sugars in the diluted hydrolysate samples. L-fucose (Sigma) was used as an internal standard for normalization of HPLC peak areas. The yield of each sugar $\left(\mathrm{Y}_{\text {sugar }}\right)$ was determined based on the sugar content (\%) in the untreated sugarcane bagasse, following Eq. (1).

$\left(\mathrm{Y}_{\text {sugar }}\right)=\left(\frac{\text { mass of solubilized sugar }}{\text { dry weight bagasse } \times \% \text { sugar }}\right) \times 100$, expressed in percentage.

\subsection{Determination of XOS total}

The total XOS (XOS Total) in the hydrolysates was determined by subtracting the amount of xylose present in the hydrolysate from the total xylose in the hydrolysates after a post-hydrolysis step (with $4 \% \mathrm{w} /$ $\mathrm{w} \mathrm{H}_{2} \mathrm{SO}_{4}$ at $121^{\circ} \mathrm{C}$ for $1 \mathrm{~h}$ in an autoclave) of the same hydrolysate, and analyzed by HPLC as previously described. The XOS total yield was calculated following Eq. (1).

\subsection{Determination of XOS with degree of polymerization up to 6}

The contents of XOS (xylobiose, xylotriose, xylotetraose, xylopentaose, and xylohexaose) in the hydrolysates were also determined by HPLC using a Dionex system (DX-500) equipped with the anion exchange column CarboPac PA100 and a ED40 electrochemical detector (gold electrode). The sample was eluted with $0.2 \mathrm{M}$ sodium hydroxide and $0.5 \mathrm{M}$ sodium acetate with linear gradient (0-25\%) for $25 \mathrm{~min}$, followed by a wash step with $0.5 \mathrm{M}$ sodium acetate for $10 \mathrm{~min}$. At the end of each run, the column was stabilized with $0.2 \mathrm{M}$ sodium hydroxide for $10 \mathrm{~min}$ also at a flow rate of $1 \mathrm{~mL} / \mathrm{min}$. The standards of xylobiose, xylotriose, xylotetraose, xylopentaose, and xylohexaose (Megazyme international) were used to quantify the concentration of XOS in the hydrolysate samples. Prior to analysis, all samples and standards were filtered through a $0.45 \mu \mathrm{m}$ HV filter (Millipore, MA, US). The yield was calculated following equation 1 .

\subsection{Determination of XOs with degree of polymerization higher than 6}

The concentration of XOS with degree of polymerization higher than 6 (XOS > 6) was determined by subtracting the xylose equivalent of xylobiose, xylotriose, xylotetraose, xylopentaose, and xylohexaose from the total xylose from the xylose equivalent of XOS total obtained 


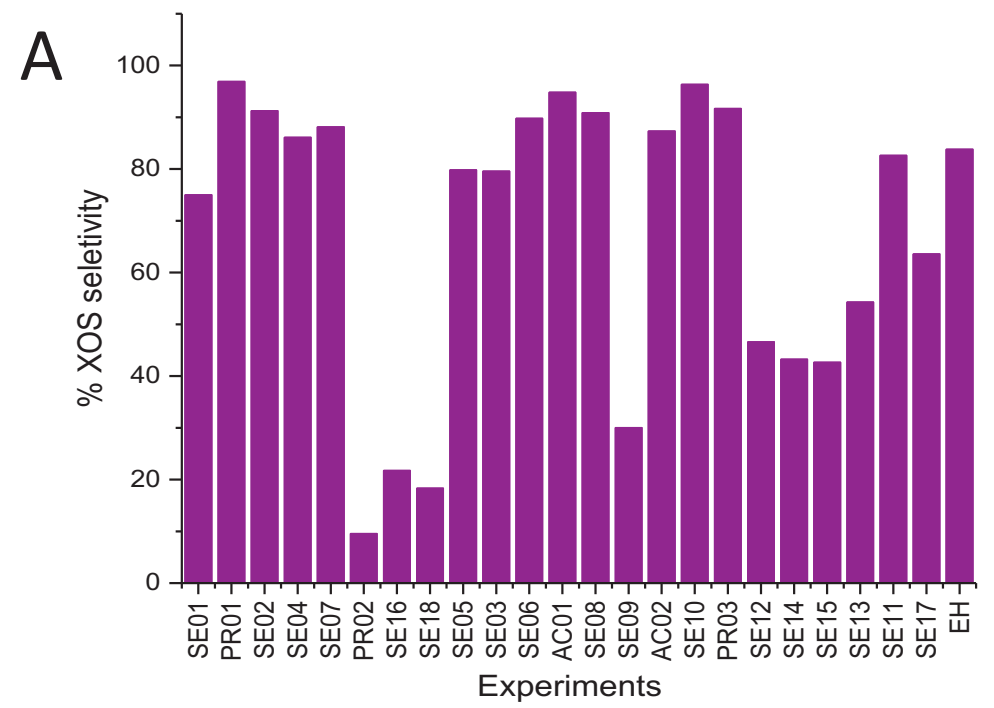

Fig. 1. (A) Xylose and XOS recovery yields from hydrolysis of the xylan in sugarcane bagasse using steam explosion $(\mathrm{SE})$, autoclave (AC) and a pressurized reaction (PR) under different processing conditions. (B) Selectivity towards production of XOS over xylose.

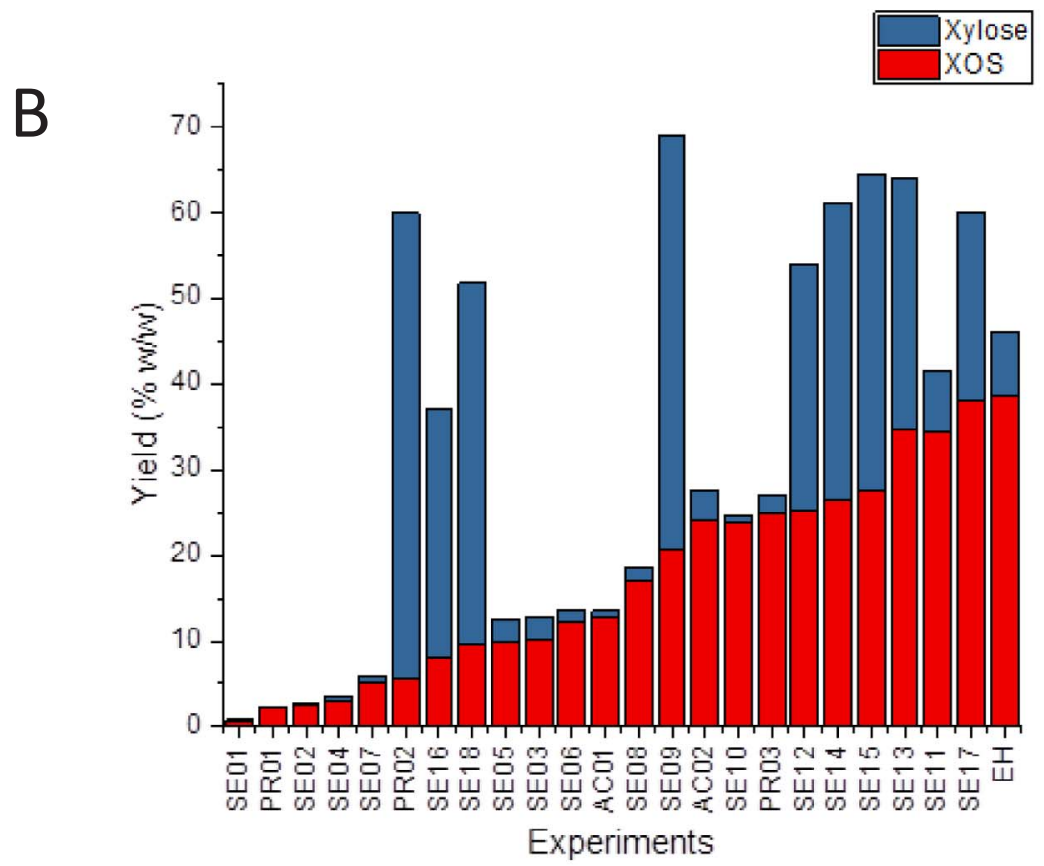

after the post-hydrolysis of the hydrolysate. The yield of XOS > 6 was calculated according to Eq. (1).

\subsection{Determination of acetic acid and furans}

Selected hydrolysates were also analyzed for the presence of acetic acid and the sugar degradation products furfural and 5-hydroxymethyl furfural using a HPLC system (ICS-5000), equipped with an Aminex HPX-87H column (Bio-Rad, Hercules, CA), a UV detector (set at a wavelength of $280 \mathrm{~nm}$ ) and eluted with $5 \mathrm{mM} \mathrm{H}_{2} \mathrm{SO}_{4}$ at a flow rate of $0.6 \mathrm{ml} / \mathrm{min}$. All samples and standards (furfural, 5-hydroxymethyl furfural, and acetic acid) were filtered through a $0.45 \mu \mathrm{m}$ syringe filter (Chromatographic Specialties, Brockville, Canada) prior to analysis.

\section{Result and discussion}

A high value carbohydrate-based product that can be made out of xylan is XOS, which indeed has been attracting increasing interest worldwide to be used as prebiotics (Gobinath et al., 2010; Mäkeläinen et al., 2010; Qing et al., 2013). This work investigates the suitability of steam explosion, an industrially relevant and relatively simple method, to, in a single step, selectively solubilize and convert the xylan-rich hemicellulose in sugarcane bagasse into XOS at high yield. Although there has been a great amount of research on hemicellulose solubilization for xylose recovery (Batalha et al., 2015; Boussarsar et al., 2009; Lavarack et al., 2002) information on xylan solubilization and recovery as XOS is limited, in particular using steam explosion. Therefore, this initial study tested eighteen different conditions to primarily evaluate the potential of SE to produce XOS at high yield, but also to establish a range of operational conditions suitable to hemicellulose solubilization and reaction products, primarily XOS, that would be essential for further optimization studies. In parallel, other laboratory-scale methods commonly used to produce XOS from sugarcane bagasse were also evaluated and compared to the SE method.

The sugarcane bagasse employed in this study was initially chemically characterized and it consisted of more than $65 \%$ polysaccharide, distributed between cellulose (40.1\%) and hemicellulose (28.6\%) (Table 3). As expected, xylan was the major hemicellulose, representing about $77 \%$ of sugarcane bagasse's hemicellulose (about $22 \%$ on bagasse's dry mass). The remaining constituents were mainly lignin and 
extractives (Table 3). Subsequently, the bagasse was submitted to different treatments for xylan solubilization according to the conditions listed in Table 1. The choice and range of the conditions and type of catalysts employed were based on a recent review on XOS production from lignocellulosic biomass (Carvalho et al., 2013) and on previous work on steam explosion pretreatment (Arantes and Saddler, 2011; Chandra et al., 2015).

A number of biomass properties and process operating conditions can influence the effectiveness of SE (Pitarelo et al., 2012; Olsen et al., 2015; Pielhop et al., 2016). Previous work on SE has shown that particle size had little influence on sugar solubilization and recovery, whereas the moisture content greatly influenced SE (Olsen et al., 2015). Therefore, prior to the treatments of the bagasse no particle size reduction was performed, only the moisture content was adjusted to $50 \%$ to ensure good uptake of the catalyst $\mathrm{SO}_{2}$.

Typically, chemical-based methods carried out in acidic medium for solubilization of the hemicellulosic fraction in lignocellulosic feedstock lead to the formation of a range of products such as monosaccharides, sugar degradation products, and products derived from extractives and acid-soluble lignin, in addition to oligosaccharides (Lavarack et al., 2002). Therefore, monosaccharides and nonsaccharide compounds must be removed in order to have a stream with high content of pure oligosaccharides for many applications (Aachary and Prapulla, 2011). Thus, besides aiming a high conversion of xylan into XOS, the composition of the hydrolysate is also an important parameter due the necessity of downstream step. Therefore, this was also taken into consideration since it would be desirable that the XOS-rich hydrolysate contained low to no levels of xylose and other monosaccharides as well as nonsaccharide products. For this reason, selectivity of the treatment for production of XOS over xylose is just as important as XOS yield.

\subsection{Steam explosion treatment}

The solubilized xylan recovered as xylose and XOS is showing in Fig. 1A. Total xylan solubilization yield as xylose and XOS varied greatly among the different methods, ranging from about $0.8 \%$ (SE01) to $60-70 \%$ (PR02, SE09, SE11-SE15, and SE17). Interestingly, even under non-optimized conditions, it was possible to produce XOS at a yield (SE11, SE13 and SE17) close to the XOS yield obtained by optimized enzymatic hydrolysis (EH) of previously alkaline extracted xylan.

The selectivity towards XOS over xylose also varied greatly among the different conditions and methods tested, ranging from about $10 \%$ to 96\% Fig. 1B. Except for SE10 experiments, that reached the highest selectivity towards XOS among all experiments with a XOS yields at $24 \%$, the highest selectivity in steam explosion (SE02-SE08), pressurized reaction (PR01), and autoclave (AC01) were detected under conditions that resulted in low XOS yield $(<20 \%)$.

For XOS yield higher than $30 \%$, only steam explosion at SE11 displayed a relatively high selectivity towards XOS (82\%), which although a nonoptimized condition, resulted in XOS yield and selectivity that were very similar to those obtained with the enzymatic hydrolysis method (EH).

A detail analysis of the processing conditions for the different xylan solubilization conditions can provide insights into the influence of the processing variables on XOS yield and selectivity (Fig. 1). For steam explosion carried out at the same condition expect for the temperature, it can be seen that increasing the temperature from $130{ }^{\circ} \mathrm{C}$ to $150{ }^{\circ} \mathrm{C}$ resulted in high recovery of XOS and xylose as observed when SE01, SE02, SE03 and SE04 were carried out at $130{ }^{\circ} \mathrm{C}$ and SE06, SE05, SE08, and SE07 at $150{ }^{\circ} \mathrm{C}$. However, further increase from $150{ }^{\circ} \mathrm{C}$ to $170{ }^{\circ} \mathrm{C}$ only slightly increased the production of XOS, but led higher increase in the production of xylose, resulting in lower selectivity towards XOS (Fig. 2). This can be seen for SE13 and SE12 carried out at $150{ }^{\circ} \mathrm{C}$ and their correspondent treatment SE15 and SE14, respectively, performed at $170^{\circ} \mathrm{C}$.

In general, the impregnation of the sugarcane bagasse with an acid catalyst $\left(\mathrm{SO}_{2}\right.$ or $\left.\mathrm{H}_{2} \mathrm{SO}_{4}\right)$ prior to steam explosion treatment resulted in higher XOS production. This can be observed for SE01, SE06, SE04 and SE07 treated in the absence of an acid catalyst (autohydrolysis) and the correspondent treatment SE02, SE05, SE03, and SE08 treated in the presence of low amount $(0.9 \%)$ of $\mathrm{SO}_{2}$. Low amount $(0.1 \%)$ of $\mathrm{H}_{2} \mathrm{SO}_{4}$ as catalyst also greatly and selectively increased XOS production from about $5.2 \%$ in autohydrolysis (SE07) to about $23.8 \%$ (SE10). In general, except for SE16, an increase in the amount of the acid catalyst from 0.9 to $3 \% \mathrm{SO}_{2}$ and from 0.1 to $1 \% \mathrm{H}_{2} \mathrm{SO}_{4}$ resulted in higher total xylan solubilization (xylose $+\mathrm{XOS}$ ), however it was followed by a great decrease in the selectivity towards XOS (Table 2). Compared to SE17, SE16 was conducted at higher concentration of the acid catalyst and resulted in much lower total xylan recovery in the hydrolysate. This result does not mean less xylan was solubilized, but due to the high severity of the treatment, the solubilized xylan was further degraded.

It seems that the influence of the reaction time on XOS and xylose production was less pronounced than catalyst and reaction temperature. For example, the xylose yield did not alter much for SE01, SE06, SE02, SE05, SE12, and SE14 treated for $15 \mathrm{~min}$ compared to their correspondent treatment SE04, SE07, SE03, SE08, SE13, and SE15 treated for $30 \mathrm{~min}$. On the other hand, the XOS yield for these same conditions at $15 \mathrm{~min}$ increased when there were carried out for $30 \mathrm{~min}$. However, it appears that the beneficial effect of increasing the reaction time decreases with an increase in temperature as can be seen for SE02 (15 min) and SE03 (30 min) performed at $130{ }^{\circ} \mathrm{C}$ with increase in XOS yield from $2.4 \%$ to $10.2 \%$, respectively, and for SE05, SE12, SE14 carried out at $150{ }^{\circ} \mathrm{C}$ for $15 \mathrm{~min}$ with XOS yield of $10.0 \%, 25.2 \%$, and $26.4 \%$, respectively, compared to SE08, SE13, SE15 also performed at $150{ }^{\circ} \mathrm{C}$ but for $30 \mathrm{~min}$, and with XOS yield $16.9 \%, 34.72 \%$ and $27.5 \%$, respectively.

SE10, SE11 and SE17 were the three SE treatments with the highest XOS yield and highest selectivity and were selected for further analysis.

\subsection{Autoclave and pressurized reactor}

At the laboratory-scale, autoclave and pressurized reactor are the two most commonly used reaction vessels to produce XOS by xylan solubilization in acid medium (Carvalho et al., 2013; Gírio et al., 2010; Otieno and Ahring, 2012; Patel et al., 2017), and they were also used in this study to compare their efficiency with the less studied, but more industrially relevant steam explosion method (Fig. 1). The conditions applied for the autoclave and pressurized rector treatments were based and very close to those employed in previous studies aiming XOS production (Aachary and Prapulla, 2009; Vallejos et al., 2015), reason why only a few conditions were tested.

In the autoclave treatment, the two conditions tested had the same reaction time and catalyst type and concentration, however the reaction temperature was different, AC01 was carried out at $121{ }^{\circ} \mathrm{C}$ and AC02 at $132^{\circ} \mathrm{C}$. Both AC01 and AC03 conditions were very selective towards XOS, but XOS yield for AC01 was only $12.8 \%$ and for AC02 about $25 \%$ (Fig. 1). These results are lower than what has been reported for XOS production from corncob using AC (Aachary and Prapulla, 2009), but much higher than various of steam explosion conditions tested in this study (i.e. SE01-SE07), about half of what was obtained with EH, similar to SE10 and much lower than SE11 (Fig. 1). These results indicate the potential of SE to produce XOS at similar or higher yield and selectivity than the autoclave method. In addition, similarly to SE, in autoclave the increase in temperature also increase the total amount of XOS and xylose in the hydrolysate, however, selectivity towards XOS decreased due to higher increase in xylose yield than XOS yield.

With the three conditions tested in the pressurized reactor (PR01, RPR02, and PR03) it was possible to solubilize and recover, in the form of xylose and XOS, between 2.2 and $60 \%$ of the xylan present in the sugarcane bagasse (Fig. 1). While PR01 seemed to be a very mild condition solubilizing only about $2.3 \%$ of the xylan, majority of it as XOS, PR02 was much more severe solubilizing about $60 \%$ of the xylan, 

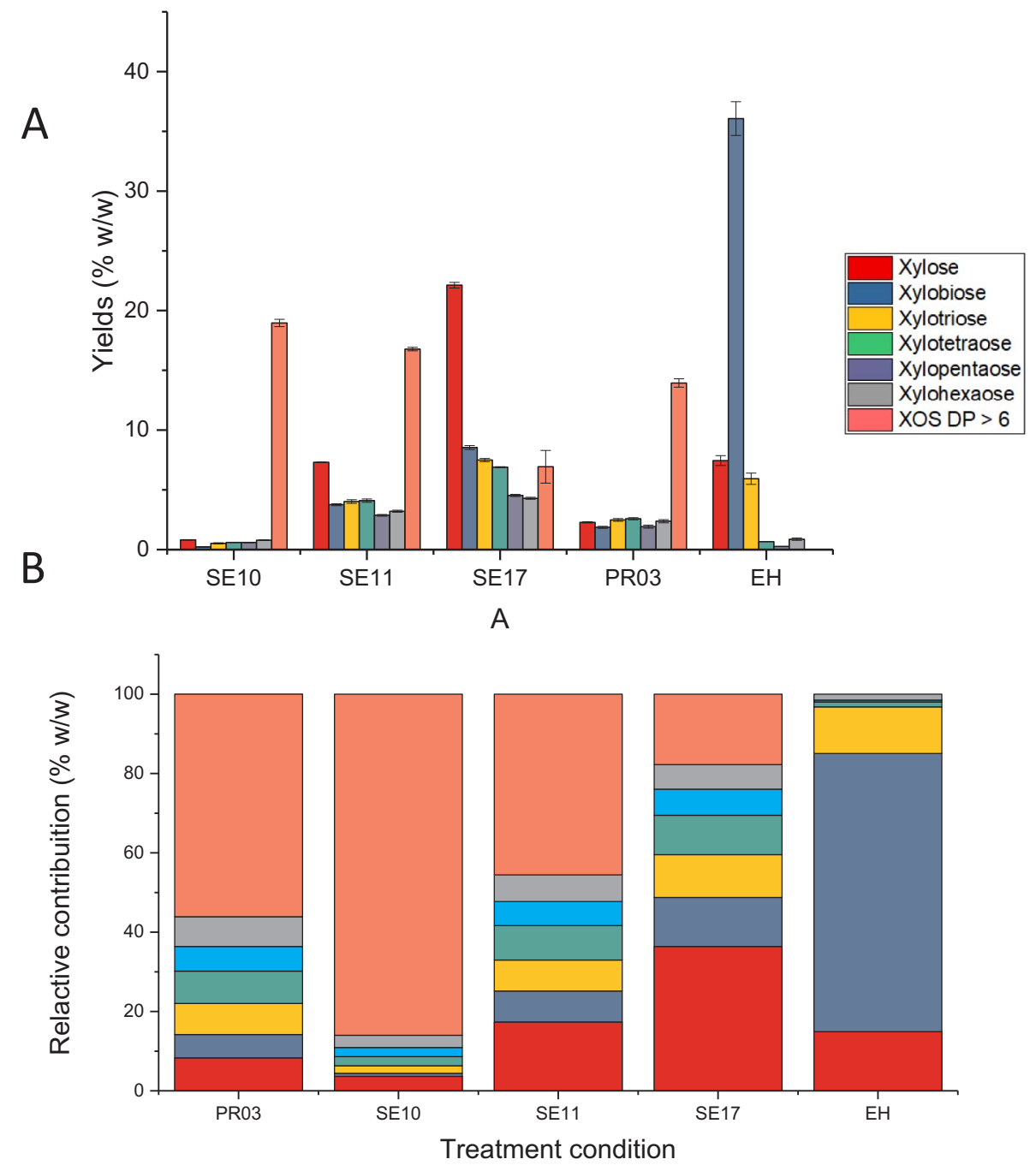

Fig. 2. (A) Composition of the XOS-rich hydrolysates in relation to the degree of polymerization DP of their XOS; (B) Relative composition of different degree of polymerization. Xylose is also indicated for comparison purpose.

Table 2

Effect of the catalyst concentration $\left(\mathrm{SO}_{2}\right.$ and $\left.\mathrm{H}_{2} \mathrm{SO}_{4}\right)$ on the recovery of XOS and xylose after steam pretreatment of sugarcane bagasse.

\begin{tabular}{|c|c|c|c|c|c|}
\hline \multirow[t]{2}{*}{ Pretreatment conditions } & \multicolumn{2}{|c|}{ Catalyst concentration $(\% \mathrm{w} / \mathrm{w})$} & \multicolumn{2}{|c|}{ Yield\% (w/w) XOS Xylose } & \multirow[t]{2}{*}{ Selectivity (\%) } \\
\hline & $\mathrm{SO}_{2}$ & $\mathrm{H}_{2} \mathrm{SO}_{4}$ & & & \\
\hline $150{ }^{\circ} \mathrm{C}, 30 \mathrm{~min}$ (SE07) & - & - & 5.2 & 0.7 & 88.1 \\
\hline $150^{\circ} \mathrm{C}, 30 \mathrm{~min}$ (SE08) & 0.9 & - & 16.9 & 1.7 & 90.8 \\
\hline $150{ }^{\circ} \mathrm{C}, 30 \mathrm{~min}$ (SE09) & 3.0 & - & 20.7 & 48.2 & 30.0 \\
\hline $150^{\circ} \mathrm{C}, 30 \mathrm{~min}$ (SE07) & - & - & 5.2 & 0.7 & 88.1 \\
\hline $150^{\circ} \mathrm{C}, 30 \mathrm{~min}$ (SE10) & - & 0.1 & 23.8 & 0.9 & 96.4 \\
\hline $150{ }^{\circ} \mathrm{C}, 30 \mathrm{~min}(\mathrm{SE} 11)$ & - & 0.5 & 34.3 & 7.2 & 82.6 \\
\hline $150^{\circ} \mathrm{C}, 30 \mathrm{~min}(\mathrm{SE} 13)$ & - & 1.0 & 34.7 & 29.2 & 54.3 \\
\hline $190^{\circ} \mathrm{C}, 5 \mathrm{~min}(\mathrm{SE} 17)$ & - & 0.5 & 38.2 & 21.9 & 63.6 \\
\hline $190^{\circ} \mathrm{C}, 5 \mathrm{~min}$ (SE16) & - & 1.0 & 8.0 & 28.9 & 21.8 \\
\hline
\end{tabular}

mainly in the form of xylose. The most suitable condition for XOS production in the PR was PR03, which solubilized about $27 \%$ of the xylan, mostly in the form of XOS (24.9\%), that is, with high selectivity for XOS. This is similar to XOS yield reported elsewhere when also using a pressured reactor (Vallejos et al., 2015). Just as observed for steam explosion and autoclave, the temperature also seems to have a high influence on xylan solubilization and products formation in the pressurized reaction. Also, similar to steam pretreatment, the concentration of the acid catalyst had a drastic influence on total xylan solubilization and recovery as XOS. This is evident when the results of PR02 (5.7\% XOS, 54.2\% xylose) and PR03 (24.9\% XOS and $2.2 \%$ xylose) are compared. These are treatment carried out at $150{ }^{\circ} \mathrm{C}$ for
15 min but the bagasse was impregnated with $0.1 \% \mathrm{H}_{2} \mathrm{SO}_{4}$ in PR02 and $0.5 \% \mathrm{H}_{2} \mathrm{SO}_{4}$ in PR03, indicating that the increase of acid concentration in the reaction causes hydrolysis of the XOS into xylose, decreasing the selectivity for XOS production by more than 100 times.

PR03 was the only suitable condition to produce significant amount of XOS with high selectivity and was also selected for further analysis. Although XOS production yield and selectivity with autoclave at condition AC02 were similar to SE10 and PR03, AC02 was not considered for further analysis since this condition requires a much longer reaction time than for the other two methods, and therefore may not be suitable for large scale production of XOS. 


\subsection{Mass balance of selected treatment conditions}

Most past work on XOS production has only considered the solubilized or extracted hemicellulosic fraction as a means to valorize the lignocellulosic feedstock. However, greater valorization opportunities lie in the production of XOS from lignocellulose within the biorefinery concept. Within this concept, the remaining solid fraction, hereafter referred to as cellulignin, obtained after hemicellulose solubilization into XOS, can also be further processed to produce a range of bioproducts such as biofuels by hydrolysis of the cellulose to glucose and further fermentation to ethanol, or bioenergy from combustion of the lignin. Therefore, estimation of the material balance following biomass treatment is fundamental for providing information on overall recovery of the individual biomass components (Hatzis et al., 1996).

In order to determine the overall recovery of the major bagasse components after hemicellulose solubilization for XOS production, a characterization of the solid fraction (WIF) and overall carbohydrate recovery in the solid and liquid fractions (WSF) were done for the previously selected steam explosion (SE10, SE11 and SE17) and pressurized reaction (PR03) conditions. The material balance was followed in terms of individual components and included the major components of the hemicellulosic fraction, cellulose, lignin, and ash, and was based on the chemical composition data for the raw sugarcane bagasse, treated WIF and WSF (Tables 3 and 4). As expected, the two major components in all treated water insoluble fractions (WIFs) were cellulose (55.3-64.3\%) and lignin (23.2-26.5) followed by the xylan (7.3-19.0) that was not hydrolyzed (Table 3). Other minor components like arabinan, galactan, and ash were also detected in the WIFs (Table 3). Compared to the untreated sugarcane bagasse (SCB), all the selected conditions showed a cellulose enrichment in the WIF, mainly because of the solubilization of the hemicellulosic components (xylan, arabinan, galactan, mannan and acetyl groups). A slight increase in lignin content was observed for conditions SE11 and SE17. The reduction of the ash content in the solid fractions was due to washing of the material during the treatment, where metallic compounds are soluble in acid pH (Qing et al., 2013).

Except for the SE10 treatment that was the most severe steam explosion treatment, practically all cellulose (greater than 92\%) was recovered in this process, mainly in the WIF as shown in (Table 4). Total recovery of xylan, which is more thermally labile than cellulose, was also relatively high (81-99.2\%), and was predominantly recovered in the WSF in the form of XOS (Table 4). All recovered and analyzed glucose (from cellulose) and xylose (from xylan) made up about $87-99 \%$ of all glucose and xylose present in the sugarcane bagasse (Table 4).

\subsection{Degradation compounds}

One characteristic of processing lignocellulosic biomass in an acidic medium is the formation of sugar degradation compounds, such as furfural and hydroxy-methyl-furfural (HMF) by dehydration reactions of pentose and hexose sugars, respectively (Hu and Ragauskas, 2012). These furan derivatives are regarded as impurities and inhibitors for many fermenting microorganisms and, if present, a purification step would be required for their removal (Zabed et al., 2016). The selected XOS-rich hydrolysates had, when detected, very low concentration of these compounds (Table 4), results similar were found by Garrote using a hydrothermal treatment and Eucalyptus globulus (Garrote et al., 1999). For example, about 0.8 and $0.4 \mathrm{~g} / \mathrm{L}$ of furfural and 0.002 and $0.004 \mathrm{~g} / \mathrm{L}$ of HMF were detected in the XOS-rich hydrolysate produced under PR03 and SE10 conditions, respectively. These compounds were not detected in the XOS-rich hydrolysates produced under SE11 and SE17 conditions, which were the two conditions that yielded the highest amount of XOS. These results indicate that because of the very low (if any) presence of furan derivatives in the XOS-rich hydrolysates, under the conditions employed in this study, it is unlikely that a purification step specifically targeting their removal would be needed.

\subsection{Characterization of XOS-rich hydrolysates}

The degradation and utilization of XOS as prebiotic by probiotic strains has been reported to be affected by the degree of polymerization (DP) (Aachary and Prapulla, 2011; Van Craeyveld et al., 2008). Because of the nonspecific hydrolysis of the xylan in acidic medium (catalyzed or unanalyzed/autohydrolysis), unlikely the enzymatic hydrolysis with endoxylanase, XOS with a variety of DPs is likely to be found in the XOS-rich hydrolysate produced using steam explosion and the pressurized reactor.

Enzymatic hydrolysis of the alkaline extracted xylan yielded mostly xylobiose (DP2), with low formation of xylotriose (DP3) and xylotetraose (DP4) (Fig. 2A). This was expected based on previous report with the Aspergilus fumigatus M51 endoxylanase used in this study (Carvalho et al., 2015). In fact, low DP XOS, predominantly xylobiose are known to be the typical products of endoxylanases (Qing and Wyman, 2011). Steam explosion and the pressurized reactor yielded XOS with varying DP, including XOS with DP between 2 and 6, and DP > 6 in addition to xylose, that was also detected in the XOS-rich hydrolyze produced by enzymatic hydrolysis (Fig. 2A and B). The DP of the XOS in the hydrolysates produced with treatments PR03 and SE10 were similar, and most XOS in these hydrolysates had DP $>6$, likely due to the mild severity condition of these treatments. Treatments SE11 and SE17 had the highest amount of XOS with DP between 2 and 6, in addition to a relatively considerable amount of xylose, in particular for SE17 (Fig. 2B).

As the interest in XOS as emerging prebiotics continues to increase over the few years, and an estimated prebiotic market of USD 3.31 billion in 2015 and compound annual rate growth (CAGR) of $11.6 \%$ until 2023 (Dover, 2016), more research has been looking not only in

Table 3

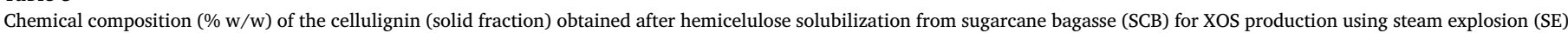
and pressurized reaction (PR) under selected conditions.

\begin{tabular}{|c|c|c|c|c|c|c|c|c|c|c|}
\hline Substrates & Arabinan & Galactan & Glucan & Xylan & Mannan & $\mathrm{AIL}^{1}$ & $\mathrm{ASL}^{2}$ & Ash & Acetyl & Total \\
\hline Raw SCB & 1.46 & 0.47 & 41.95 & 21.6 & 0.8 & 23.27 & 1.47 & 3.5 & 3.5 & 98.02 \\
\hline Sd & 0.05 & 0.01 & 1.00 & 0.6 & 0.03 & 0.05 & 0.04 & 0.5 & 0.2 & \\
\hline SE10 & 0.97 & 0.20 & 55.3 & 19.0 & 0.86 & 23.6 & 0.86 & 2.6 & 1.54 & 104.8 \\
\hline $\mathrm{Sd}$ & 0.06 & 0.02 & 1.30 & 1.7 & 0.01 & 0.9 & 0.02 & 0.8 & 0.5 & \\
\hline SE11 & 0.74 & 0.12 & 54.4 & 18.1 & 0.53 & 26.5 & 0.69 & 2.9 & 1.23 & 105.2 \\
\hline $\mathrm{Sd}$ & 0.02 & 0.003 & 1.40 & 0.45 & 0.01 & 0.1 & 0.09 & 0.3 & 0.3 & \\
\hline SE17 & 0.41 & 0.05 & 64.3 & 7.3 & 0.55 & 26.0 & 0.75 & 2.6 & 0 & 102.0 \\
\hline Sd & 0.01 & 0.002 & 0.45 & 0.13 & 0.008 & 4.3 & 0.02 & 0.2 & 0 & \\
\hline PR03 & 0.73 & 0.12 & 58.5 & 17.1 & 0.52 & 23.2 & 0.84 & 2.2 & 1.2 & 104.4 \\
\hline Sd & 0.02 & 0.004 & 1.30 & 0.45 & 0.03 & 2.3 & 0.1 & 0.1 & 0.2 & \\
\hline
\end{tabular}

\footnotetext{
${ }^{1}$ AIL: acid insoluble lignin.

${ }^{2}$ ASL: acid soluble lignin; Sd: standard deviation.
} 
Table 4

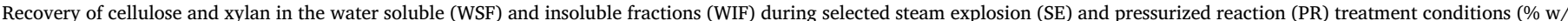
w).

\begin{tabular}{|c|c|c|c|c|c|c|c|c|c|c|c|}
\hline \multirow[t]{3}{*}{ Treatment } & \multicolumn{4}{|c|}{ Cellulose (\%) } & \multicolumn{4}{|c|}{ Xylan (\%) } & \multicolumn{2}{|c|}{ Degradation products $(\% \mathrm{w} / \mathrm{w})$} & \multirow[t]{3}{*}{$\mathrm{Xyl}+$ Glu recovery } \\
\hline & \multirow[t]{2}{*}{ WIF } & \multicolumn{2}{|l|}{ WSF } & \multirow[t]{2}{*}{ Total } & \multirow[t]{2}{*}{ WIF } & \multicolumn{2}{|l|}{ WSF } & \multirow[t]{2}{*}{ Total } & & & \\
\hline & & Mono $^{1}$ & Oligo $^{2}$ & & & Mono $^{1}$ & Oligo $^{2}$ & & Furfural & $\mathrm{HMF}^{3}$ & \\
\hline SE10 & 88.2 & 0.00 & 2.1 & 90.3 & 58.7 & 0.8 & 21.4 & 81.0 & 0.044 & 0.004 & 87.1 \\
\hline SE11 & 92.4 & 0.00 & 2.7 & 95.1 & 57.7 & 7.2 & 34.3 & 99.2 & BDL & BDL & 96.5 \\
\hline SE17 & 95.3 & 0.15 & 3.2 & 98.6 & 23.0 & 21.9 & 38.2 & 83.1 & BLD & BDL & 93.3 \\
\hline PR03 & 103.3 & 0.00 & 2.5 & 105.8 & 58.6 & 2.3 & 24.9 & 85.7 & 0.082 & 0.002 & 98.9 \\
\hline
\end{tabular}

${ }^{1}$ Mono: monomeric form.

${ }^{2}$ Oligo: oligomeric form.

${ }^{3}$ HMF: Hydroxymethylfurfural; Xyl: xylose; Glu: glucose; BDL: Below detection limit.

the production of XOS but also their prebiotic potential. As a result, one important characteristic of a XOS mixture that has been reported is that XOS with varying DPs. Mäkeläinen et al. showed that XOS with DP varying from 2 to 10 has high prebiotic activity (Mäkeläinen et al., 2010). On the other hand, Moura et al. showed that XOS with lower DP (DP 2-3) displayed higher prebiotic activity than XOS with high DP (Moura et al., 2007). Although these studies seem contradictory, both DP range have been reported to be ideal for supplementation for human and animal feeding (Samanta et al., 2015).

Based on the fact that the XOS hydrolysates generated in this study seem suitable to be used as prebiotic oligosaccharides due to the DP range in the XOS hydrolysates, further research should focus not only on optimizing XOS yield and selectivity, but also on evaluating their prebiotic property as well as whether the already high purity achieved is adequate for application as prebiotic or additional purification is required.

\section{Conclusion}

Steam explosion has been proven to be a viable process to treat lignocellulose for hemicellulose solubilization and it is already employed at commercial scale. Based on the findings reported here, it can be concluded that steam explosion is also a suitable method for selective solubilization of xylan into XOS at high yield. This can be achieved by tailoring the operating conditions (reaction time, temperature, catalyst type and concentration) of the steam explosion process, which can result in a XOS-rich hydrolysate with similar or even better characteristics for prebiotic application than the commonly used laboratory scale methods.

\section{Acknowledgements}

V Arantes would like to thank the Brazilian National Council for Scientific and Technological Development (CNPq) (Brazil) for the financial support for this work (grants 308715/2015-2 and 429895/ 2016-0). AF Carvalho thanks CNPq for her postdoc fellowship and financial support for her stay at the University of British Columbia (Canada), and Fundação de Amparo à Pesquisa do Estado de São Paulo (FAPESP) for financial support of this work in Brazil. WF Marcondes also would like to thank CNPq for his master's fellowship.

\section{References}

Aachary, A.A., Prapulla, S.G., 2009. Value addition to corncob: production and characterization of xylooligosaccharides from alkali pretreated lignin-saccharide complex using Aspergillus oryzae MTCC 5154. Bioresour. Technol. 100, 991-995. http://dx. doi.org/10.1016/j.biortech.2008.06.050.

Aachary, A.A., Prapulla, S.G., 2011. Xylooligosaccharides (XOS) as an emerging prebiotic: microbial synthesis, utilization, structural characterization, bioactive properties, and applications. Compr. Rev. Food Sci. Food Saf. 10, 2-16. http://dx.doi.org/10.1111/j. 1541-4337.2010.00135.x.
Abdul Khalil, H.P.S., Bhat, A.H., Ireana Yusra, A.F., 2012. Green composites from sustainable cellulose nanofibrils: a review. Carbohydr. Polym. 87, 963-979. http://dx. doi.org/10.1016/j.carbpol.2011.08.078.

Akpinar, O., Erdogan, K., Bostanci, S., 2009. Enzymatic production of Xylooligosaccharide from selected agricultural wastes. Food Bioprod. Process. 87, 145-151. http://dx.doi.org/10.1016/j.fbp.2008.09.002.

Arantes, V., Saddler, J.N., 2011. Cellulose accessibility limits the effectiveness of minimum cellulase loading on the efficient hydrolysis of pretreated lignocellulosic substrates. Biotechnol. Biofuels 4, 3. http://dx.doi.org/10.1186/1754-6834-4-3.

Bacovsky, D., Ludwiczek, N., Ognissanto, M., Wörgetter, M., 2013. Status of advanced biofuels demonstration facilities in 2012. A Rep. To Iea Bioenergy Task 39, 1-209.

Batalha, L.A.R., Han, Q., Jameel, H., Chang, H., Colodette, J.L., Borges Gomes, F.J., 2015. Production of fermentable sugars from sugarcane bagasse by enzymatic hydrolysis after autohydrolysis and mechanical refining. Bioresour. Technol. 180, 97-105. http://dx.doi.org/10.1016/j.biortech.2014.12.060.

Boussarsar, H., Rogé, B., Mathlouthi, M., 2009. Optimization of sugarcane bagasse conversion by hydrothermal treatment for the recovery of xylose. Bioresour. Technol. 100, 6537-6542. http://dx.doi.org/10.1016/j.biortech.2009.07.019.

Carvalheiro, F., Duarte, L.C., Gírio, F.M., 2008. Hemicellulose biorefineries: a review on biomass pretreatments. J. Sci. Ind. Res. (India) 67, 849-864.

Carvalho, A.F.A., Oliva-Neto, P. De, da Silva, D.F., Pastore, G.M., 2013. Xylo-oligosaccharides from lignocellulosic materials: chemical structure, health benefits and production by chemical and enzymatic hydrolysis. Food Res. Int. 51, 75-85. http:// dx.doi.org/10.1016/j.foodres.2012.11.021.

Carvalho, A.F.A., De Oliva-Neto, P., Zaghetto de Almeida, P., Bueno da Silva, J., Escaramboni, B., Pastore, G.M., 2015. Screening of Xylanolytic aspergillus fumigatus for prebiotic Xylooligosaccharide production using bagasse. Food Technol. Biotechnol. 53, 428-435. http://dx.doi.org/10.17113/ftb.53.04.15.4160.

Chandra, R.P., Arantes, V., Saddler, J., 2015. Steam pretreatment of agricultural residues facilitates hemicellulose recovery while enhancing enzyme accessibility to cellulose. Bioresour. Technol. 185, 302-307. http://dx.doi.org/10.1016/j.biortech.2015.02. 106.

Dence, C.W., 1992. The Determination of Lignin. In: Lin, S.Y., Dence, C.W. (Eds.), Methods in Lignin Chemistry. Springer Berlin Heidelberg, Berlin, Heidelberg, pp. 33-61 10.1007/978-3-642-74065-73.

Dover D., 2016. Prebiotics Market Size Forecast to Exceed USD 7.5 Billion by 2023: Global Market Insights Inc. Glob. Mark. Insights Inc. May 09.

Ebringerová, A., Heinze, T., 2000. Xylan and xylan derivatives - biopolymers with valuable properties, 1. Naturally occurring xylans structures, isolation procedures and properties. Macromol. Rapid Commun. 21, 542-556 10.1002/1521-3927(20000601) 21:9 < 542::AID-MARC542 > 3.3.CO;2-Z.

Figueiredo, F.C. De, Flavia, A., Carvalho, A., Campioni, T.S., Oliva-Neto, P. De, 2016 Chemical input reduction in the arabinoxylan and lignocellulose alkaline extraction and xylooligosaccharides production. Bioresour. Technol. 228, 164-170. http://dx. doi.org/10.1016/j.biortech.2016.12.097.

Garrote, G., Domínguez, H., Parajó, J.C., 1999. Mild autohydrolysis: an environmentally friendly technology for xylooligosaccharide production from wood. J. Chem. Technol. Biotechnol. 74, 1101-1109 10.1002/(SICI)1097-4660(199911) 74:11 < 1101::AID-JCTB146 > 3.0.CO;2-M.

Gírio, F.M., Fonseca, C., Carvalheiro, F., Duarte, L.C., Marques, S., Bogel-Łukasik, R., 2010. Hemicelluloses for fuel ethanol: a review. Bioresour. Technol. 101, 4775-4800. http://dx.doi.org/10.1016/j.biortech.2010.01.088.

Gobinath, D., Madhu, A.N., Prashant, G., Srinivasan, K., Prapulla, S.G., 2010. Beneficial effect of xylo-oligosaccharides and fructo-oligosaccharides in streptozotocin-induced diabetic rats. Br. J. Nutr. 104, 40-47. http://dx.doi.org/10.1017/ S0007114510000243.

Hatzis, C., Riley, C., Philippidis, G.P., 1996. Detailed material balance and ethanol yield calculations for the biomass-to-ethanol conversion process. Appl. Biochem. Biotechnol. 57, 443. http://dx.doi.org/10.1007/BF02941725.

Hendriks, A.T.W.M., Zeeman, G., 2009. Pretreatments to enhance the digestibility of lignocellulosic biomass. Bioresour. Technol. 100, 10-18. http://dx.doi.org/10.1016/ j.biortech.2008.05.027.

Hu, F., Ragauskas, A., 2012. Pretreatment and Lignocellulosic Chemistry. BioEnergy Res. 5, 1043-1066. http://dx.doi.org/10.1007/s12155-012-9208-0.

Javier, P.F.I., Óscar, G., Sanz-Aparicio, J., Díaz, P., 2007. Xylanases: Molecular Properties 
and Applications. In: Industrial Enzymes. Springer Netherlands, Dordrecht, pp. 65-82 10.1007/1-4020-5377-0 5.

Kamm, B., Kamm, M., 2004. Principles of biorefineries. Appl. Microbiol. Biotechnol. 64, 137-145. http://dx.doi.org/10.1007/s00253-003-1537-7.

Ketelaere, B., Broekaert, W.F., Delcour, J.A., Courtin, C.M., 2008. Structurally different wheat-derived arabinoxylooligosaccharides have different prebiotic and fermentation properties in rats. J. Nutr. 138, 2348-2355. http://dx.doi.org/10.3945/jn.108. 094367.

Lavarack B.P., G.J., G., D., R., 2002. The acid hydrolysis of sugarcane bagasse hemicellulose to produce xylose, arabinose,glucose and other products [WWW Document]. Biomass and Bioenergy.

Lee, H.V., Hamid, S.B.A., Zain, S.K., 2014. Conversion of lignocellulosic biomass to nanocellulose. Struct. Chem. Process. Sci. World J. 1-20. http://dx.doi.org/10.1155/ 2014/631013.

Mäkeläinen, H., et al., 2010. Xylo-oligosaccharides and lactitol promote the growth of Bifidobacterium lactis and Lactobacillus species in pure cultures. Benef. Microbes 1, 139-148. http://dx.doi.org/10.3920/BM2009.0029.

Mäkeläinen, H., Forssten, S., Saarinen, M., Stowell, J., Rautonen, N., Ouwehand, A., 2010. Xylo-oligosaccharides enhance the growth of bifidobacteria and Bifidobacterium lactis in a simulated colon model. Benef. Microbes 1, 81-91. http://dx.doi.org/10. 3920/BM2009.0025.

Manorach, K., Poonsrisawat, A., Viriya-empikul, N., Laosiripojana, N., 2015 Optimization of sub-critical water pretreatment for enzymatic hydrolysis of sugarcane bagasse. Energy Procedia 79, 937-942. http://dx.doi.org/10.1016/j.egypro. 2015.11.590.

Moura, P., Barata, R., Carvalheiro, F., Gírio, F., Loureiro-Dias, M.C., Esteves, M.P., 2007. In vitro fermentation of xylo-oligosaccharides from corn cobs autohydrolysis by Bifidobacterium and Lactobacillus strains. LWT - Food Sci. Technol. 40, 963-972. http://dx.doi.org/10.1016/j.lwt.2006.07.013.

Nimz, H.H., 1984. Wood-chemistry, ultrastructure, reactions. 314 314. Holz Als RohUnd Werkst. 42. http://dx.doi.org/10.1007/BF02608943.

Olsen, C., Arantes, V., Saddler, J., 2012. The use of predictive models to optimize sugar recovery obtained after the steam pre-treatment of softwoods. Biofuels. Bioprod. Biorefining 6, 534-548. http://dx.doi.org/10.1002/bbb.1347.

Olsen, C., Arantes, V., Saddler, J., 2015. Optimization of chip size and moisture content to obtain high, combined sugar recovery after sulfur dioxide-catalyzed steam pretreatment of softwood and enzymatic hydrolysis of the cellulosic component. Bioresour. Technol. 187, 288-298. http://dx.doi.org/10.1016/j.biortech.2015.03.084.

Otieno, D.O., Ahring, B.K., 2012. The potential for oligosaccharide production from the hemicellulose fraction of biomasses through pretreatment processes: xylooligosaccharides (XOS), arabinooligosaccharides (AOS), and mannooligosaccharides (MOS). Carbohydr. Res. 360, 84-92. http://dx.doi.org/10.1016/j.carres.2012.07. 017.

Panthapulakkal, S., Kirk, D., Sain, M., 2015. Alkaline Extraction of Xylan from Wood Using Microwave and Conventional Heating 41330 1-10. http://dx.doi.org/10. 1002/app.41330.

Patel, H., Chapla, D., Shah, A., 2017. Bioconversion of pretreated sugarcane bagasse using enzymatic and acid followed by enzymatic hydrolysis approaches for bioethanol production. Renew. Energy 109, 323-331. http://dx.doi.org/10.1016/j.renene.2017. 03.057 .
Pedersen, M., Meyer, A.S., 2010. Lignocellulose pretreatment severity - relating $\mathrm{pH}$ to biomatrix opening. N. Biotechnol. 27, 739-750. http://dx.doi.org/10.1016/j.nbt. 2010.05.003.

Pielhop, T., Amgarten, J., von Rohr, P.R., Studer, M.H., 2016. Steam explosion pretreatment of softwood: the effect of the explosive decompression on enzymatic digestibility. Biotechnol. Biofuels 9, 152. http://dx.doi.org/10.1186/s13068-0160567-1.

Pitarelo, A., Silva, T., Peralta-Zamora, P., Ramos, L., 2012. Effect of moisture content in the steam treatment and enzymatic hydrolysis of sugarcane bagasse. Quim. Nova 35, 1502-1509. http://dx.doi.org/10.1590/S0100-40422012000800003.

Qing, Q., Wyman, C.E., 2011. Hydrolysis of different chain length xylooliogmers by cellulase and hemicellulase. Bioresour. Technol. 102, 1359-1366. http://dx.doi.org/ 10.1016/j.biortech.2010.09.001.

Qing, Q., Li, H., Kumar, R., Wyman, C.E., 2013. Xylooligosaccharides production, quantification, and characterization in context of lignocellulosic biomass pretreatment. Aqueous pretreat. Plant Biomass Biol. Chem. Convers. Fuels Chem. 391-415.

Rocha, G.J.M., Martín, C., da Silva, V.F.N., Gómez, E.O., Gonçalves, A.R., 2012. Mass balance of pilot-scale pretreatment of sugarcane bagasse by steam explosion followed by alkaline delignification. Bioresour. Technol. 111, 447-452. http://dx.doi.org/10. 1016/j.biortech.2012.02.005.

Samanta, A.K., Jayapal, N., Jayaram, C., Roy, S., Kolte, A.P., Senani, S., Sridhar, M., 2015. Xylooligosaccharides as prebiotics from agricultural by-products: production and applications. Bioact. Carbohydr. Diet. Fibre 5, 62-71. http://dx.doi.org/10.1016/j. bcdf.2014.12.003.

Santucci, B.S., Maziero, P., Rabelo, S.C., Curvelo, A.A.S., Pimenta, M.T.B., 2015. Autohydrolysis of hemicelluloses from sugarcane bagasse during hydrothermal pretreatment: a kinetic assessment. BioEnergy Res. 8, 1778-1787. http://dx.doi.org/10. 1007/s12155-015-9632-z.

Schell, D.J., Farmer, J., Newman, M., Mcmillan, J.D., 2003. Dilute-sulfuric acid pretreatment of corn stover in pilot-scale reactor: investigation of yields, kinetics, and enzymatic digestibilities of solids. Appl. Biochem. Biotechnol. 105, 69-86. http://dx. doi.org/10.1385/ABAB:105:1-3:69.

Sluiter, A., Hames, B., Ruiz, R., Scarlata, C., Sluiter, J., Templeton, D., 2008. Determination of sugars, byproducts, and degradation products in liquid fraction process samples - NREL/TP-510-42623. NREL 1-14.

Vallejos, M.E., Felissia, F.E., Kruyeniski, J., Area, M.C., 2015. Kinetic study of the extraction of hemicellulosic carbohydrates from sugarcane bagasse by hot water treatment. Ind. Crops Prod. 67, 1-6. http://dx.doi.org/10.1016/j.indcrop.2014.12. 058 .

Vázquez, M., Alonso, J., Domínguez, H., Parajó, J., 2000. Xylooligosaccharides: manufacture and applications. Trends Food Sci. Technol. 11, 387-393. http://dx.doi.org/ 10.1016/S0924-2244(01)00031-0.

Zabed, H., Sahu, J.N., Boyce, A.N., Faruq, G., 2016. Fuel ethanol production from lignocellulosic biomass: an overview on feedstocks and technological approaches. Renew. Sustain. Energy Rev. 66, 751-774. http://dx.doi.org/10.1016/j.rser.2016.08. 038 .

Zilliox, C., Debeire, P., 1998. Hydrolysis of wheat straw by a thermostable endoxylanase: Adsorption and kinetic studies. Enzyme Microb. Technol. 22, 58-63. http://dx.doi. org/10.1016/S0141-0229(97)00105-1. 